\title{
Problemas De Comparação De Razões: Uma Avaliação Do Raciocínio Proporcional De Alunos Do Sexto Ano
}

\author{
Ratios Comparison Problems: An Evaluation Of Proportional \\ Reasoning Of Sixth Degree Students
}

\author{
Odalea Aparecida Viana \\ Universidade Federal de Uberlândia - (UFU) \\ Juliene Azevedo Miranda \\ Colégio Educação - (Ituiutaba, MG)
}

\begin{abstract}
Resumo
O artigo compara as estratégias de resolução de dois problemas de comparação utilizadas por alunos do sexto ano em dois momentos: antes e após uma intervenção didática aplicada com o objetivo de introduzir os conceitos de razão e proporção. Foram sujeitos 15 alunos de uma escola particular e a intervenção foi planejada no âmbito do mestrado profissional e aplicada durante as aulas em período normal. A análise indicou que, embora boa parte dos alunos já dispusesse, antes da intervenção didática, de esquemas de covariação e de invariância, isto não facilitou a solução do primeiro problema. Após a intervenção, vários alunos apresentaram os esquemas recompostos e enriquecidos em linguagem simbólica adequada, mas nem todos acertaram e justificaram o problema. $\mathrm{Na}$ perspectiva de Gérard Vergnaud, esta investigação permite mostrar que o processo de aquisição dos conceitos de razão e proporção é de natureza bastante complexa, e que são necessárias muitas situações para que esses conceitos e os procedimentos requeridos para a solução de problemas adquiram, de fato, sentido para o aluno.
\end{abstract}

Palavras-chave: Raciocínio proporcional. Resolução de problemas. Razão e proporção.

\begin{abstract}
This paper compares strategies of solving two comparison problems utilized by students from sixth degree of elementary school in two distinct moments: before and after a didactic intervention applied with the objective of introducing the concepts of ratio and proportion. The subjects were 15 students of a private school. The intervention was planned in the context of professional master's degree and applied during the classes in normal period. The analysis indicated that, although a considerable number of students already had covariation and invariance schemes before the didactic intervention, this factor didn't facilitate the solving of the first problem. After intervention, several students presented the schemes in such a way that they were recomposed and enriched in symbolic language, but not all of them gave the correct answer to the problem nor justified it. According to Gérard Vergnaud perspective, this investigation reveals that the process of acquiring the concepts of ratio and proportion has a very complex nature, and many situations are required so that those concepts and the procedures necessary to problem solving get an effective meaning to the student.
\end{abstract}

Keywords: Proportional Reasoning. Problem Solving. Ratio and Proportionality. 
requer a compreensão da relação constante entre duas grandezas (a invariância) e a noção de que estas grandezas variam em conjunto (a covariância).

A literatura aponta que os alunos se valem de várias estratégias para resolver os problemas envolvendo o raciocínio proporcional, tais como: estratégias aditivas, taxa unitária, relações de covariação, produto cruzado etc. Certos problemas de comparação podem ser resolvidos por crianças, antes mesmo de aprenderem formalmente os conceitos de razão e proporção, especialmente em situações em que se pode utilizar o referencial metade (BOYER et al, 2008; SPINILLO, 1992, 1993).

Em Viana e Miranda (2015), foram analisadas as estratégias utilizadas por alunos do sexto ano para resolver problemas de comparação e de valor omisso, tendo sido encontrados procedimentos distintos nos dois casos e, ainda, mais erros nos problemas de comparação. Como os sujeitos daquela pesquisa também participaram de uma intervenção didática no âmbito do mestrado profissional em ensino de ciências e matemática (PPGECM/UFU) - que tinha por finalidade introduzir os conceitos de razão e proporção - questionou-se se haveria mudanças de estratégias para os problemas de comparação quando comparadas as situações antes e após a intervenção.

Dessa forma, a presente investigação pretendeu analisar, junto a alunos do sexto ano que ainda não tinham aprendido formalmente o conteúdo relativo à razão e proporção, as estratégias que foram utilizadas para resolver problemas de comparação em dois momentos: antes e após uma intervenção didática, visando introduzir os conceitos citados.

Serão apresentadas, de forma resumida, as atividades que compuseram a sequência didática aplicada na intervenção e que foram elaboradas de acordo com os pressupostos teóricos de Gérard Vergnaud, em que os conceitos de razão e proporção fazem parte das chamadas estruturas multiplicativas. Para Vergnaud (1990), os conceitos são formados num conjunto que envolve: (a) as situações, responsáveis pelo sentido atribuído ao conceito; (b) os invariantes operatórios contidos nos esquemas cognitivos que fazem com que a ação do sujeito seja operatória e (c) as representações simbólicas. Como a teoria sustenta que os alunos empregam esquemas cognitivos para resolver certa classe de situações, pretende-se analisar as estratégias utilizadas na solução de problemas de comparação e identificar a possível mudança de esquemas com base nas representações simbólicas produzidas nas soluções apresentadas nos dois momentos citados. 


\section{O Raciocínio Proporcional}

Documentos oficiais indicam a importância do desenvolvimento do raciocínio proporcional antes da formalização do conceito de razão e proporção - tema pertinente ao sétimo ano do ensino fundamental. Para a Base Nacional Curricular Comum (BNCC), a proporcionalidade - tema que promove articulações entre os diferentes campos que compõem a Matemática e que pode ser evidenciada em muitas ações cotidianas, como vendas e trocas mercantis, balanços químicos, representações gráficas etc. - deve estar presente no estudo das operações com os números naturais, da representação fracionária dos números racionais, de áreas, de funções e de probabilidade (BRASIL, 2016b, p.224).

Indicando que não se trata da simples mecanização de procedimentos - como, por exemplo, a regra de três - vários autores da área de Educação Matemática estudam a complexidade do raciocínio proporcional, o que pode ser visto em Costa e Ponte (2008), Lamon (1993, 2005), Lesh et al (1988), Maranhão e Machado (2011), Morton (2014), Spinillo (1992, 1993, 2002) e Torre et al (2013), entre outros.

Faz parte do desenvolvimento do raciocínio proporcional a compreensão de duas relações nomeadas por Ponte et al. (2010) : (a) invariância, que é a relação constante entre duas grandezas variáveis discretas ou contínuas e (b) covariação, que é relativa à variação em conjunto das mesmas grandezas. As mesmas relações são chamadas, respectivamente, de “análise horizontal ou relação externa" e de "análise vertical ou relação interna", por Vergnaud (2009).

Ao menos dois tipos de problemas podem avaliar o raciocínio proporcional de alunos: os de valor omisso (ou tarefas de incógnita) e os de comparação. No primeiro caso, são dados $\mathrm{A}, \mathrm{B}$ e $\mathrm{C}$ da proporção $\mathrm{A}: \mathrm{B}=\mathrm{C}: \mathrm{X}$ e é solicitado o valor do termo desconhecido "X". A literatura aponta que os alunos podem se valer de estratégias aditivas ou multiplicativas (produto cruzado, taxa unitária etc.) para resolvê-los, conforme pode ser visto em Torre et al. (2013), Ponte et al. (2010), Magina et al. (2014). Um exemplo desse tipo de problema é mostrado na Figura 3, em que são ilustradas as relações de invariância e de covariação. 


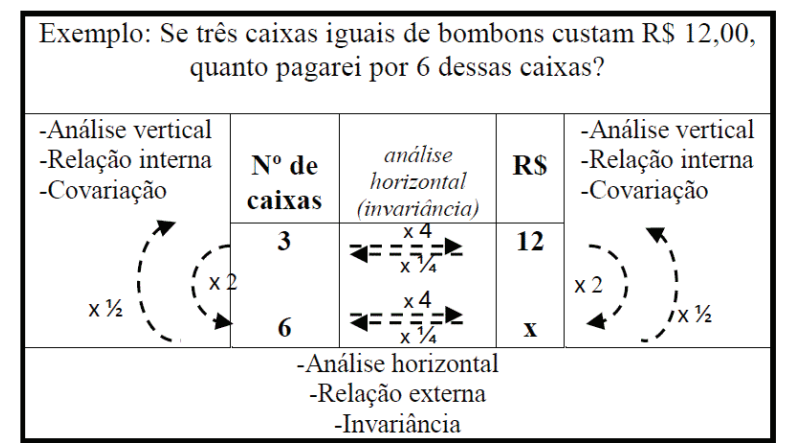

Figura 3: Problema de valor omisso e relações envolvidas Fonte: Viana e Miranda (2016, p.197)

Já nos problemas de comparação, tema da presente pesquisa, o indivíduo deve identificar duas grandezas e quatro valores, A, B, C e D e definir se as razões A:B e C:D são equivalentes e, em caso contrário, qual é maior ou menor. Para solucionar a questão, é necessário estabelecer uma relação de primeira ordem no primeiro par de valores (A:B) e uma outra relação de primeira ordem no segundo par (C:D); a comparação entre elas consiste na relação entre essas relações, ou seja, numa relação de segunda ordem. Um exemplo é o problema clássico: "Júlia misturou 2 copos de suco concentrado em 4 copos de água e Paula misturou 3 copos de suco em 5 de água. Qual suco é mais forte?". Tarefas desse tipo foram analisadas por Spinillo (1992, 1993, 2002), que encontrou dificuldades das crianças para estabelecer relações de segunda ordem e realizar comparações parte-todo. A autora encontrou que muitas delas utilizavam o referencial "metade" em tarefas de proporção com dimensões contínuas, o que favorecia o estabelecimento das relações de segunda ordem. A Figura 4 ilustra os elementos envolvidos e as relações de primeira ordem (parte-parte) a serem estabelecidas em vários tipos de problemas de comparação envolvendo variáveis discretas.

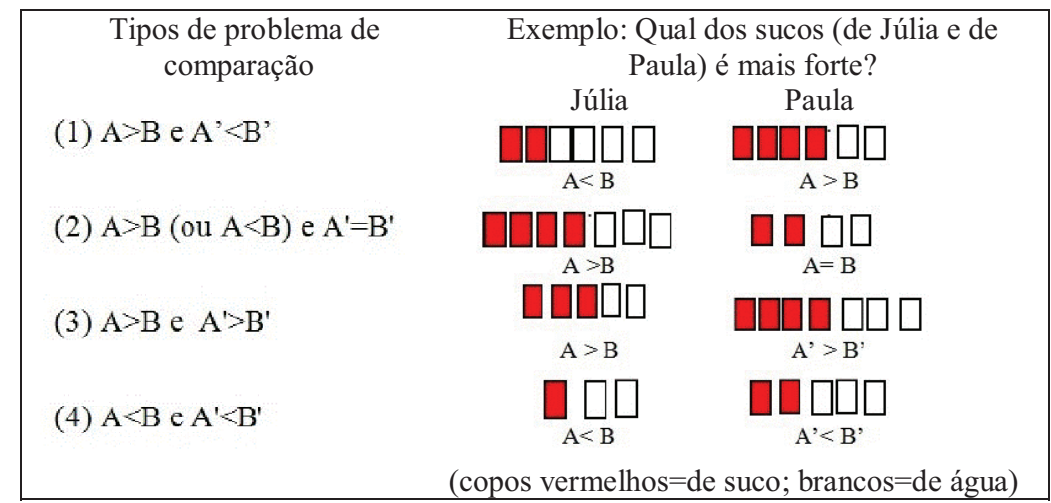

Figura 4: Tipos de problemas de comparação conforme relações de primeira ordem envolvendo inteiros discretos Fonte: Viana e Miranda (2016, p.198)

As crianças parecem ter mais dificuldade com quantidades discretas que contínuas em tarefas de comparação (BOYER et al., 2008); as análises de Jeong et al (2011) indicaram que 
problemas com quantidades discretas no contexto de um jogo que envolvia noções de probabilidade (tiro ao alvo) foram resolvidos erroneamente porque muitos alunos contavam o número de chances (tiros) ou o número de acertos no alvo, mas não estabeleciam relações de segunda ordem.

As soluções dadas a estes problemas - que envolvem as chamadas estruturas multiplicativas ${ }^{1}$, conforme Vergnaud (1990) - dependem dos esquemas cognitivos que a criança tem disponíveis nas diversas situações a serem resolvidas. Para o autor, esquema é uma organização invariante das operações mentais para uma determinada classe de situações: para aquela em que o sujeito já tem em seu repertório as habilidades necessárias, os procedimentos são mais automatizados e estão organizados por um esquema único; já na classe de situações para as quais o sujeito não dispõe de todas as competências necessárias, há um esboço e uma combinação de esquemas e trata-se de um processo que necessariamente é acompanhado de descobertas.

Apesar de não evocarem todos os esquemas disponíveis pelo sujeito, as representações simbólicas - que podem ser expressas por meio de palavras, desenhos, expressões numéricas e algébricas etc.- contribuem no processo de conceitualização matemática. No caso desta pesquisa, pretendeu-se compreender, na possível mudança das estratégias empregadas pelos alunos e por meio das representações simbólicas produzidas, em que consiste, do ponto de vista cognitivo, a operacionalidade dos conceitos de razão e proporção na situação de comparação. Procurou-se evidenciar, também, algumas combinações de esquemas, já que os problemas de comparação propostos pareciam compor uma situação para a qual os alunos não dispunham de todas as competências necessárias.

\section{Método}

A presente investigação teve por objetivo comparar as estratégias utilizadas por alunos para resolver problemas de comparação em dois momentos: antes e após uma intervenção didática que objetivava introduzir os conceitos de razão e proporção.

Foram sujeitos 15 alunos do sexto ano do ensino fundamental de uma escola particular, que ainda não tinham aprendido formalmente os conceitos citados, caracterizando uma amostra de conveniência. Foi realizada uma intervenção didática formada por uma série de atividades

\footnotetext{
${ }^{1} \mathrm{O}$ campo conceitual das estruturas multiplicativas refere-se ao conjunto de problemas ou situações cuja análise e tratamento requerem vários tipos de conceitos, procedimentos e representações simbólicas, os quais se encontram em estreita conexão uns com os outros, destacando-se: as operações de multiplicação e divisão, fração, razão, proporção, número racional, as funções lineares e não lineares, o espaço vetorial e a análise dimensional.
} 
que visavam introduzir aqueles conceitos e estas foram elaboradas e aplicadas no âmbito do mestrado profissional em ensino de ciências e matemática (PPGECM/UFU). Como a pesquisadora era também professora de matemática da turma, a pesquisa - que pode ser vista em Miranda (2016) - caracterizou-se como pesquisa do professor: esta objetiva entender a complexidade do fenômeno de aprendizagem em sala de aula, a partir da experiência do próprio pesquisador (CARNEIRO, 2008; MOREIRA \& NARDI, 2009).

Conforme descrito em Miranda (2016), a intervenção didática foi aplicada entre os meses de outubro e novembro de 2015, totalizando sete aulas regulares ${ }^{2}$. Em uma aula anterior ao início das atividades, foi aplicada uma avaliação de desempenho tipo lápis e papel, a fim de avaliar o raciocínio proporcional (Avaliação 1), ou seja, verificar quais esquemas eram empregados pelos alunos para resolver quatro problemas: dois de valor omisso (em que eram dados três dos valores que compunham uma proporção e era pedido o quarto) e outros dois de comparação (em que os alunos deveriam indicar, sem apresentação formal, qual razão era maior, menor ou se eram iguais). As questões tinham por base a classificação de problemas de raciocínio proporcional feita por Lesh et al. (1988), e amplamente utilizada por pesquisadores do tema.

A intervenção deu-se na forma de atividades em que foram utilizadas situaçõesproblema, com mediação da professora, de modo a favorecer o estabelecimento das relações de covariação e de invariância de grandezas (PONTE et al., 2010). Considerando a situaçãoproblema como um questionamento para o qual não se espera resposta correta de imediato, buscou-se explorar as ideias envolvidas e o estabelecimento de certas relações entre as quantidades. Assim, cada etapa da intervenção didática consistiu na apresentação de um problema e de um roteiro de atividades que organizavam a discussão a ser mediada pela professora e que permitiam aos alunos representar as relações estabelecidas por meio de desenhos, tabelas e frases preenchidas com palavras ou símbolos matemáticos.

Ao final da intervenção, foi aplicada uma segunda avaliação (Avaliação 2) formada por problemas que apresentavam certa semelhança com aqueles apresentados na primeira avaliação, de modo a identificar os esquemas utilizados pelos alunos.

A intervenção didática foi organizada conforme o Quadro 1.

\footnotetext{
${ }^{2}$ Ao todo, 25 alunos participaram da intervenção, mas foram selecionados apenas 15 alunos frequentes em todas as atividades, inclusive nas duas avaliações.
} 


\begin{tabular}{|c|c|c|c|}
\hline \multicolumn{2}{|r|}{ Descrição } & Número de aulas & Data \\
\hline \multirow[t]{2}{*}{ Avaliação 1} & & 1 & $17 / 09$ \\
\hline & $1^{\mathrm{a}}$ ) Problema das urnas & 2 & $22 / 10$ \\
\hline \multirow[t]{3}{*}{ Atividades } & $2^{a}$ ) Problema do colar & 2 & $29 / 10$ \\
\hline & $3^{a}$ ) Problema dos quadrados & 2 & $12 / 11$ \\
\hline & $\left.4^{a}\right)$ Sim ou não? & 1 & $18 / 11$ \\
\hline Avaliação 2 & & 1 & $26 / 11$ \\
\hline
\end{tabular}

Quadro 1: Cronograma das atividades da intervenção didática Fonte: Elaboração da autora

A participação dos alunos foi autorizada por seus responsáveis e pela direção da escola através da assinatura de um termo de consentimento. As folhas com as resoluções dos problemas e com as representações feitas pelos alunos foram recolhidas para análise. Além disso, logo após cada aula ministrada, a professora anotou em seu caderno os diálogos que serviram para analisar as relações estabelecidas pelos alunos.

A análise das estratégias empregadas na solução dos problemas da Avaliação 1 foi descrita em Viana e Miranda (2016). Para o presente trabalho, serão retomadas as respostas dadas a um dos problemas de comparação da Avaliação 1, que serão comparadas com as respostas dadas ao problema de comparação constante na Avaliação 2, de modo a analisar as possíveis mudanças de esquemas cognitivos por meio das palavras e representações simbólicas matemáticas produzidas pelos alunos. As palavras e símbolos matemáticos utilizados pelos sujeitos (aqui chamados de S1, S2 etc.) foram escaneados e transcritos para apresentação neste texto.

\section{Uma Síntese Da Intervenção}

A primeira atividade foi iniciada por meio da situação-problema exposta no Quadro 2.

\begin{tabular}{|c|c|}
\hline $\begin{array}{l}\text { Ana, Benê e Cadu vão encher simultaneamente urnas com } \\
\text { bolas pretas e brancas. } \\
\text { Ana vai fazer assim: para cada bola preta, ela vai colocar } 2 \\
\text { brancas. } \\
\text { Benê vai fazer assim: } 4 \text { brancas para cada bola preta colocada. } \\
\text { Cadu: para cada } 2 \text { pretas, vai colocar } 3 \text { brancas. }\end{array}$ & $\begin{array}{l}\text { Quando Ana, Benê e Cadu estavam } \\
\text { enchendo as urnas, o sinal para o } \\
\text { intervalo bateu; então eles perceberam } \\
\text { que estavam com o mesmo número de } \\
\text { bolas brancas. } \\
\text { Então, quem ficou com mais bolas } \\
\text { pretas? }\end{array}$ \\
\hline
\end{tabular}

Quadro 2: Problema das Urnas

Fonte: Elaboração das autoras, com base em Miranda (2016)

A professora escolheu aleatoriamente três alunos para interpretar o problema utilizando urnas e bolas brancas e pretas (Figura 5a). 


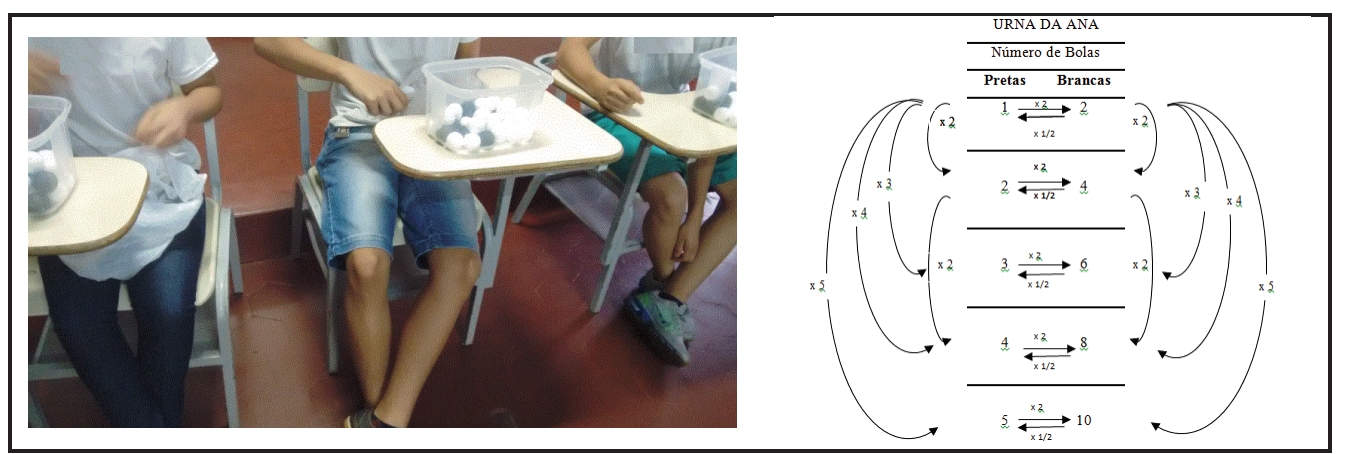

Figura 5: (a) Urnas e bolas utilizadas para interpretar o Problema das urnas e (b) Esquemas de covariação e invariância das grandezas na urna de Ana

Fonte: Miranda (2016)

Após a leitura e a interpretação do problema em conjunto com os alunos, a professora entregou a ficha de Ana (Figura 6). Auxiliados pela mediação da docente, os discentes preencheram a ficha conjuntamente. Na lousa, a professora fez os esquemas de covariação e invariância das grandezas na urna de Ana, conforme mostrado na Figura 5-b. Em seguida, foram entregues as fichas de Benê e de Cadu (Figura 6), que foram preenchidas em duplas, sendo que, ao final, a professora representou na lousa os quadros com os esquemas de covariação e invariância das grandezas referentes às respectivas urnas, socializando as respostas.

Nota-se que o problema das urnas visava levar os alunos a estabelecer relações de covariância, especialmente quando multiplicavam cada linha da tabela por dois, três etc., para determinar a próxima linha, e também quando completavam frases como: "se dobrar o número de bolas pretas também dobra o número de bolas brancas". Objetivava também o estabelecimento das relações de invariância, quando os alunos preenchiam a tabela com a razão invariável entre as grandezas de cada linha (bolas pretas para bolas brancas). Outras frases a serem preenchidas requeriam representações simbólicas na forma de palavras e expressões para as ideias que estavam sendo introduzidas; assim, duas grandezas que variavam em conjunto eram chamadas de grandezas proporcionais, na razão identificável no enunciado do problema. Nota-se que as fichas de Ana, Benê e Cadu mantinham a mesma estrutura, mas, na sequência, as frases apareciam de maneira incompleta para serem preenchidas corretamente.

$\mathrm{Na}$ aula seguinte, a professora retomou, por meio do datashow, as fichas preenchidas e entregou a ficha com a questão final (Figura 6). As tabelas que haviam sido compostas para cada urna foram sintetizadas nesta ficha final. Após explicações da professora, os alunos chegaram à conclusão que poderiam representar a razão entre bolas pretas e brancas da seguinte maneira: Ana $\rightarrow 1: 2=6: 12$; Benê $\rightarrow 1: 4=3: 12$; Cadu $\rightarrow 2: 3=8: 12$, o que igualaria o número de bolas brancas. Como 3:12<6:12<8:12, então 1:4 $<1: 2<2: 3$ e concluíram que quem ficou 
com mais bolas pretas foi Cadu.

Na segunda e na terceira atividade, Problema do colar e Problema dos quadrados, respectivamente, foram retomados os esquemas de covariação e de invariância. As questões propunham situações que requeriam os esquemas já utilizados, mas também desafiavam os alunos com situações novas. Exemplos de novos esquemas podem ser verificados nas questões que requeriam o cálculo do valor omisso em uma proporção (Problema do colar) e naquelas em que os alunos deveriam decidir, dadas duas grandezas, se elas eram ou não proporcionais (Problema dos quadrados). A Figura 7 mostra os dois problemas. 


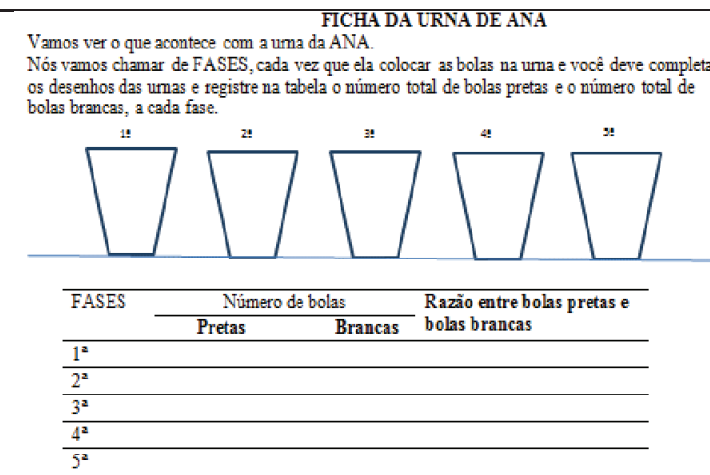

1) Se dobrar o nimero de bolas pretas, também ............... o numero de bolas brancas 2) Se triplicar o numero de bolas pretas, também.............. o número de bolas brancas. 3) Se multiplicar por 5 o número de bolas pretas, on ${ }^{\circ}$ de bolas brancas fica multiplicado por
4) Podemos verificar que o número de bolas pretas e o número de bolas brancas variam 5) Neste problema, as bolas pretas e as bolas brancas sâo chamadas de GRANDEZAS

6) As grandezas bolas pretas e bolas brancas são proporcionais na RAZÄO 1 para 2

brolas pretas são proporcionais na RAZÄO2 para 1 (_..... brancas para ...... preta) ou $2: 1$ ou

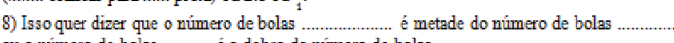
gro o númeto de bolas....... é o dobro do nímero de bolas..........

\section{FICHA DA URNA DO CAD}

$V$ amos ver o que acontece com a urna do BENE.

Nós vamos chamar de FASES, cada vez que ele colocar as bolas na uma e você deve completart os desenhos das unas e registre na tabela o número total de bolas pretas e o número total de bolas brancas, a cada fase.
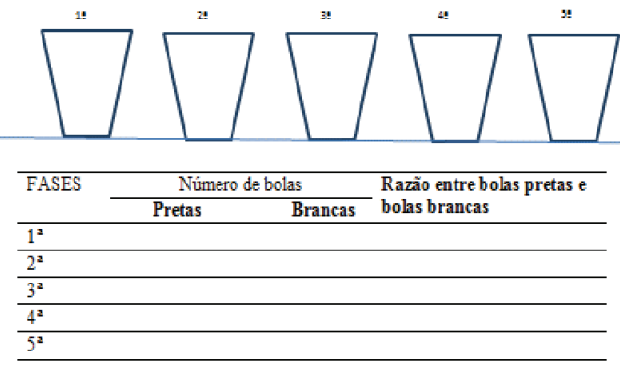

1) Se dobrar o número de bolas pretas, também o número de bolas brancas.

2) Se triplicar o numero de bolas pretas, tambem ................ o numero de bolas brancas. 3) Se multiplicar por 50 número de bolas pretas, o n$^{\circ}$ de bolas brancas fica multiplicado por 4) Podemos verificar que 0 uúmero de bolas pretas e 0 número de bolas brancas variam

5) Neste problema, as bolas pretas e as bolas brancas sâo chamadas de GRANDEZAS

6) As grandezas bolas pretas e bolas brancas são proporcionais na RAZÄO ... para.

7) As grandezas bolas brancas e bolas pretas são proporcionais na RAZÄO ... para.

..... brancas para ...... preta) ou ... ou ...

है donimero de bolas

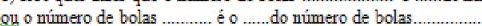

FICHA

Nós vamos chamar de FASES, cada vez que ele colocar as bolas na urna e vocé deve completar os desenhos das umas e registre na tabela o número total de bolas pretas e o número total de bolas brancas, a cada fase.
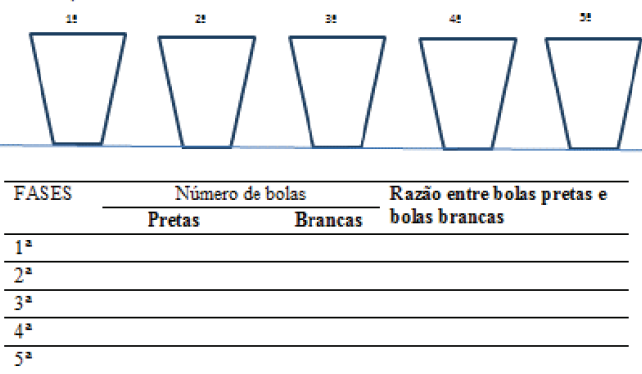

1) Se dobrar o número de bolas pretas, também ……....... o número de bolas brancas. Se triplicar o uúmero de bolas pretas, também.................. o número de bolas brancas. Se multiplicar por 50 número de bolas pretas, o $\mathrm{n}^{\circ}$ de bolas brancas fica multiplicado por ... Podemos verificar que o número de bolas pretas e o número de bolas brancas variam 5) Neste problema, as bolas pretas e as bolas brancas são chamadas de GRANDEZAS 6) As gramdezas bolas pretas e bolas brancas sâo proporcionais na RAZĀO 1 para ...

As grandezas bolas brancas e bolas pretas são proporcionais na RAZĀO ... para. I brancas para .... preta) ou ... ou bolas ….............. é .......do número de bolas ............. oho nimero de boles do número de bolas.............

\section{FICHA COM A QUESTAंO FINAL}

Se as unas estiverem com o mesmo número de bolas brancas, qual terá mais bolas pretas? Tente responder por meio da tabela

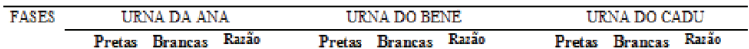

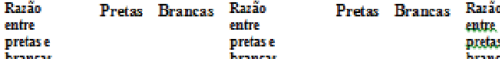
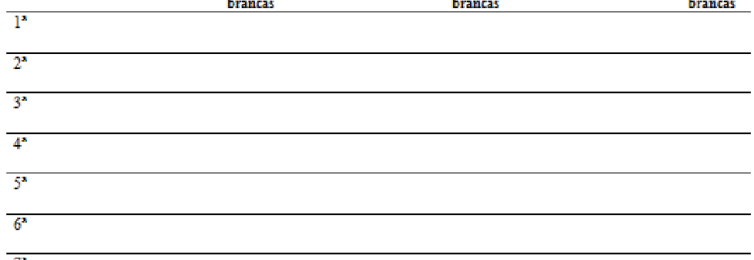

O que vocé concluiu? Quando baten o siual, quem ficou com mais bolas pretas? Vocé pode tentar tesponder fazendo uma comparaç̆o entre as fazõos que foram obtidas uas unas de Aua, Benê e Cadu. Resposta:

Figura 6: Fichas utilizadas na primeira atividade da intervenção

Fonte: Miranda (2016) 


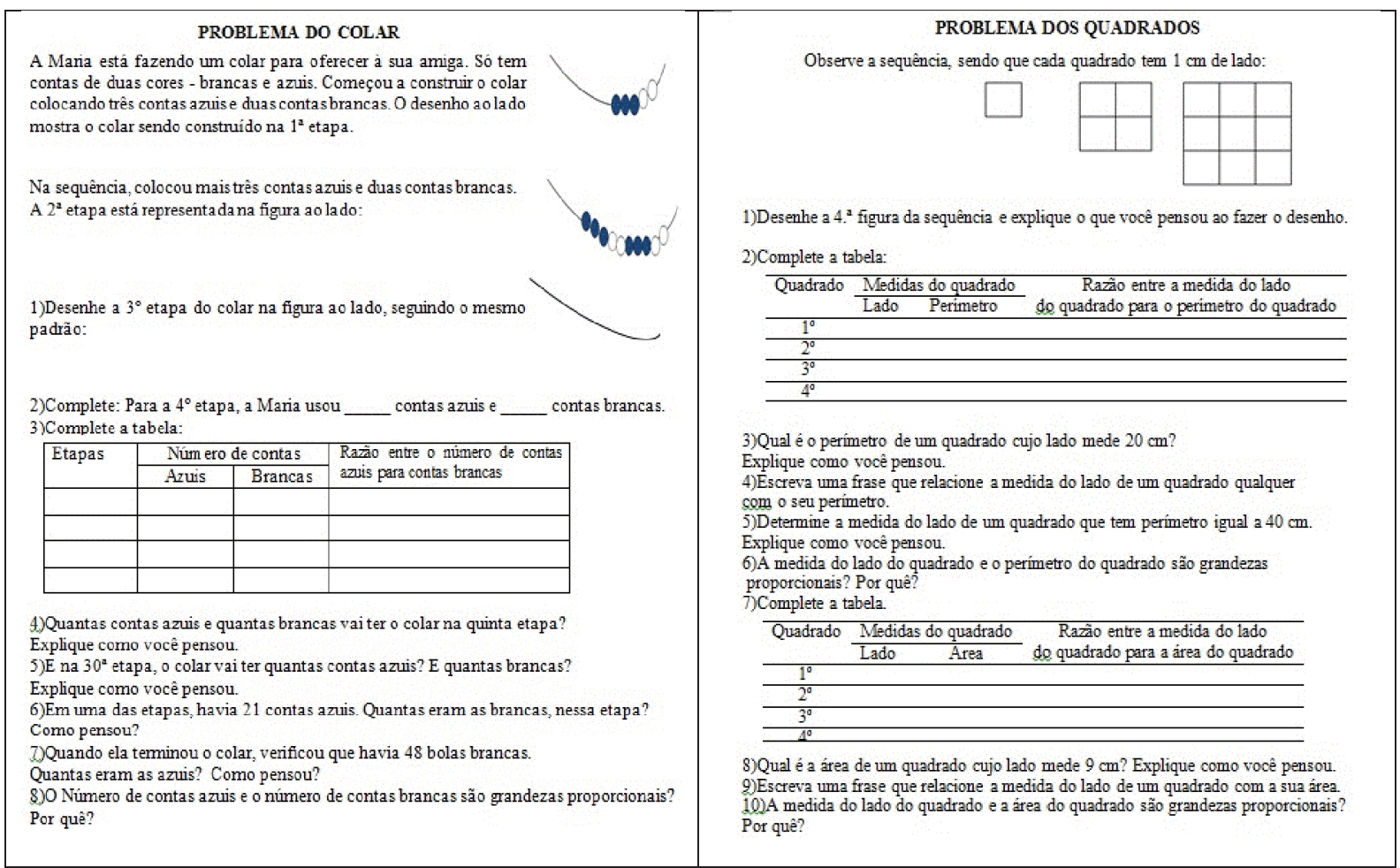

Figura 7: Problema do colar e Problema dos quadrados Fonte: Miranda (2016)

Finalmente, foi aplicada a Avaliação 2, denominada por Mais problemas, cujas questões requeriam os esquemas já trabalhados, mas agora em situações distintas das tratadas em sala de aula. Entre as questões propostas, destaca-se o item (b) da questão denominada Probleminhas, destacada na Figura 8.

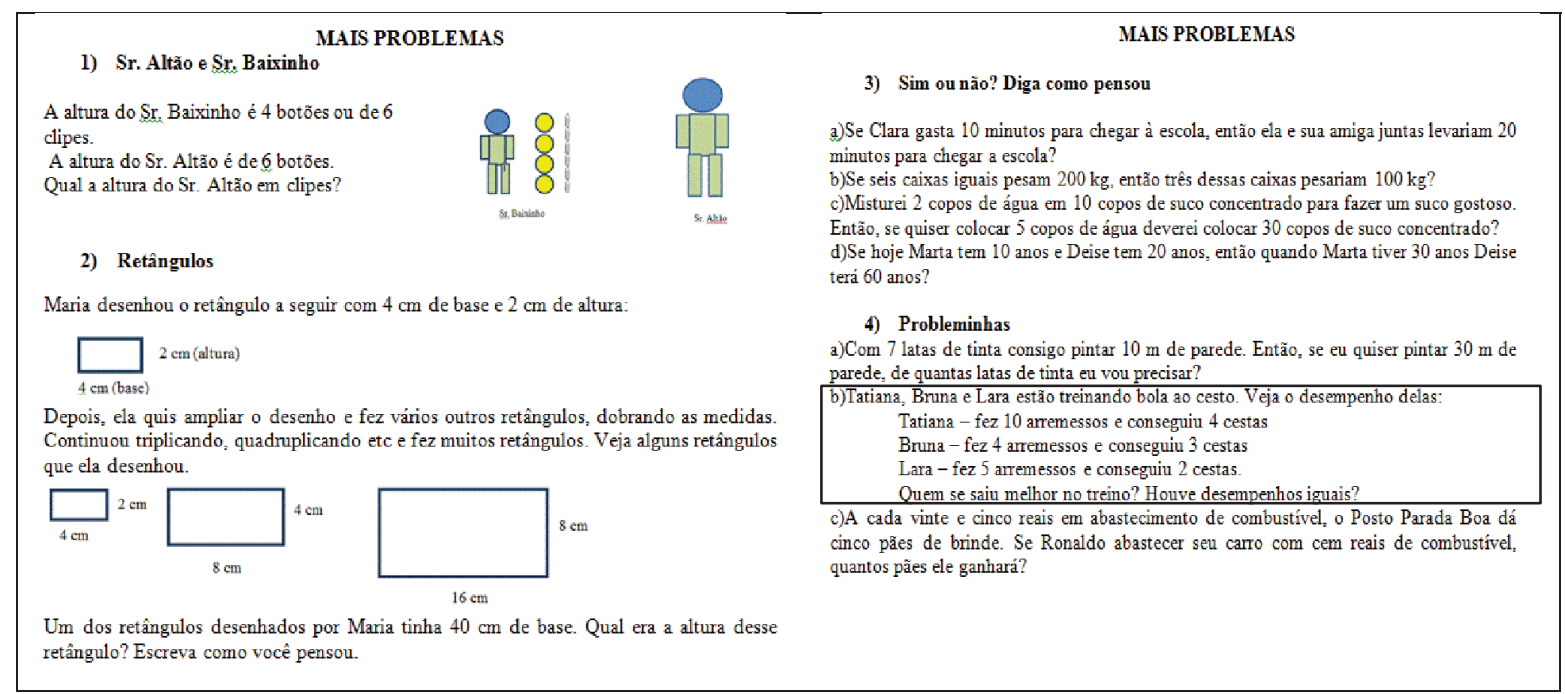

Figura 8: Avaliação 2 e o problema destacado Fonte: Miranda (2016) 


\section{Resultados: A Comparação Entre As Estratégias}

Conforme já apontado, pretendeu-se comparar as estratégias empregadas pelos alunos para resolver dois problemas de comparação: um apresentado antes da intervenção didática brevemente relatada neste texto - e o outro constante da avaliação aplicada após a intervenção. Os dois problemas são mostrados no Quadro 3.

\begin{tabular}{|c|c|}
\hline Problema 1 , anterior à intervenção & Problema 2, posterior à intervenção \\
\hline $\begin{array}{l}\text { Três meninos, Ronaldo, Felipe e Jairo, estavam } \\
\text { treinando chutes a gol. Veja o que aconteceu: } \\
\text { Ronaldo: de cada } 2 \text { chutes, fazia } 1 \text { gol. } \\
\text { Felipe: de cada } 3 \text { chutes, fazia } 2 \text { gols. } \\
\text { Jairo: de cada } 6 \text { chutes, fazia } 3 \text { gols. } \\
\text { Observando as informações acima, responda: } \\
\text { a)Qual menino se saiu melhor no treino, isto é, } \\
\text { qual deles teve o melhor desempenho? } \\
\text { b)Houve desempenhos iguais? Explique como } \\
\text { você pensou. }\end{array}$ & $\begin{array}{l}\text { Tatiana, Bruna e Lara estão treinando bola ao } \\
\text { cesto. Veja o desempenho delas: } \\
\text { Tatiana - fez } 10 \text { arremessos e conseguiu } 4 \text { cestas } \\
\text { Bruna - fez } 4 \text { arremessos e conseguiu } 3 \text { cestas } \\
\text { Lara - fez } 5 \text { arremessos e conseguiu } 2 \text { cestas. } \\
\text { Quem se saiu melhor no treino? Houve } \\
\text { desempenhos iguais? }\end{array}$ \\
\hline
\end{tabular}

Quadro 3: Problemas de comparação
Fonte: Elaboração das autoras, com base em Miranda (2016)

Os dois sujeitos que utilizaram o referencial metade para responder acertadamente o Problema 1, também acertaram o Problema 2. No Quadro 4, tem-se as respostas de S1 e S2 aos dois problemas: note-se que ambos se referiram ao único erro e à pequena quantidade de tentativas de Bruna (Quadro 4).

\begin{tabular}{|c|c|c|}
\hline Sujeito & $\begin{array}{c}\text { Problema 1 } \\
\text { a)Quem teve melhor desempenho? } \\
\text { b)Houve desempenhos iguais? }\end{array}$ & $\begin{array}{c}\text { Problema 2 } \\
\text { a)Quem teve melhor desempenho? } \\
\text { b)Houve desempenhos iguais? }\end{array}$ \\
\hline S1 & $\begin{array}{l}\text { a)Felipe, pois os outros só acertaram metade } \\
\text { dos chutes e Felipe mais da metade. } \\
\text { b) Sim, Ronaldo e Jairo, os dois acertaram } \\
\text { metade dos chutes. }\end{array}$ & $\begin{array}{l}\text { a)Bruna, pois ela com menos arremessos do } \\
\text { que suas colegas só errou uma cesta e suas } \\
\text { amigas erraram mais. } \\
\text { b) O desempenho de Lara e Tatiana foram } \\
\text { iguais. }\end{array}$ \\
\hline S2 & $\begin{array}{l}\text { a) Felipe, de cada } 3 \text { chutes fazia } 2 \text { gols. } \\
\text { b) Sim, Ronaldo e Jairo, eles acertaram a } \\
\text { metade do que chutou. }\end{array}$ & $\begin{array}{l}\text { a) A Bruna que errou } 1 . \\
\text { b)Lara e Tatiana. }\end{array}$ \\
\hline
\end{tabular}

Quadro 4: Respostas utilizando o referencial metade Fonte: Elaboração das autoras

Levar em conta o número de erros ou o de acertos foi a estratégia adotada por vários sujeitos no Problema 1. Se isso garantiu resposta correta para indicar qual o melhor desempenho, a mesma estratégia levou ao erro na determinação de possíveis desempenhos equivalentes: S3, S4 e S5 disseram que Felipe e Ronaldo teriam desempenhos iguais porque ambos erraram 1 gol. S6 simula chances iguais para determinar os desempenhos. Já no Problema 2, os mesmos se valem das razões para acertar as respostas (Quadro 5). 


\begin{tabular}{|c|c|c|}
\hline Sujeito & $\begin{array}{l}\text { Problema } 1 \\
\text { a)Quem teve melhor desempenho? } \\
\text { b)Houve desempenhos iguais? }\end{array}$ & $\begin{array}{l}\text { Problema } 2 \\
\text { a)Quem teve melhor desempenho? } \\
\text { b)Houve desempenhos iguais? }\end{array}$ \\
\hline S3 & $\begin{array}{l}\text { a) O Felipe teve uma quantidade de chutes, mas } \\
\text { apenas errou } 1 \text {. } \\
\text { b)Felipe e Ronaldo, pois os dois erraram só } 1 \text { gol. Já } \\
\text { o Jairo errou } 3 \text {. }\end{array}$ & 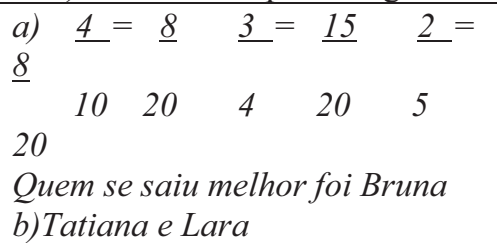 \\
\hline S4 & $\begin{array}{l}\text { a) O Felipe, pois ele fez mais gols que o Ronaldo, mas } \\
\text { Jairo fez mais gols, porém Jairo teve mais } \\
\text { oportunidade que Felipe. } \\
\text { b) Sim o de Ronaldo e Felipe. Porque em todos os } \\
\text { chutes dos dois faltou } 1 \text { gol para o aproveitamento dos } \\
\text { dois ser } 100 \% \text {. }\end{array}$ & $\begin{array}{l}\text { a) } 10: 4=20: 8 \\
4: 3=20: 15 \\
5: 2=20: 8 \\
\text { Bruna se saiu melhor no treino. } \\
\text { b) E houve desempenho igual entre } \\
\text { Tatiana e Lara. }\end{array}$ \\
\hline S5 & $\begin{array}{l}\text { a) Felipe teve mais desempenho pois ele teve três } \\
\text { chances para fazer o gol e só acertou } 2 \text { gols, então ele } \\
\text { teve mais desempenho. } \\
\text { b) Sim, Felipe e Ronaldo, pois Ronaldo teve } 2 \text { chutes, } \\
\text { então ele acertou 2; como Felipe teve mais chances de } \\
\text { que Ronaldo era como se tirasse uma chance de } \\
\text { Felipe e dai ele ia ficar com um gol como o Ronaldo. }\end{array}$ & $\begin{array}{l}\text { a) } 10: 4=20: 8 \\
4: 3=20: 15 \\
5: 2=20: 8 \\
\text { Bruna se saiu melhor. } \\
\text { b) Tatiana e Lara }\end{array}$ \\
\hline S6 & $\begin{array}{l}\text { a)Felipe, pois se por exemplo cada um tivesse seis } \\
\text { chances, Ronaldo e Jairo fariam } 3 \text { e Felipe } 4 . \\
\text { b) Sim, Ronaldo e Jairo }\end{array}$ & $\begin{array}{l}\text { a) } \frac{4}{10}=\frac{8}{20} \quad \underline{3}=\frac{15}{4} \quad \underline{2}=\underline{8} \\
\text { Foi a Bruna. } \\
\text { b)Tatiana e Lara }\end{array}$ \\
\hline
\end{tabular}

Quadro 5: Respostas que utilizaram razões no Problema 2 Fonte: Elaboração das autoras

Contar os acertos e/ou erros levou S7, S8 e S9 a equívocos nos dois problemas, apesar de S7 e S8 terem acertado que Bruna teve melhor desempenho nas cestas (Quadro 6).

\begin{tabular}{|c|c|c|}
\hline Sujeito & $\begin{array}{c}\text { Problema 1 } \\
\text { a)Quem teve melhor desempenho? } \\
\text { b)Houve desempenhos iguais? }\end{array}$ & $\begin{array}{c}\text { Problema 2 } \\
\text { a)Quem teve melhor desempenho? } \\
\text { b)Houve desempenhos iguais? }\end{array}$ \\
\hline S7 & $\begin{array}{l}\text { a)Ronaldo. } \\
\text { b)Sim, do Ronaldo e Felipe. Ronaldo de } 2 \text { chutes fez } 1 \\
\text { gol. Felipe de } 3 \text { chutes } 2 \text { gols, isso equivale ao mesmo } \\
\text { tanto. }\end{array}$ & $\begin{array}{l}\text { a)Bruna se saiu melhor. } \\
\text { b)Sim, o de Lara e Tatiana. }\end{array}$ \\
\hline S8 & $\begin{array}{l}\text { a)Ronaldo e Felipe. } \\
\text { b) Sim, Ronaldo e Felipe, eu pensei assim, Ronaldo } \\
\text { errou um e fez outro, errou só um e Felipe também. }\end{array}$ & $\begin{array}{l}\text { a)Bruna, pois ela errou só um } \\
\text { arremesso. } \\
\text { b) Não teve desempenho igual. }\end{array}$ \\
\hline S9 & $\begin{array}{l}\text { a)Ronaldo e Felipe, pois Ronaldo só perdeu uma } \\
\text { chance e Ronaldo também. } \\
\text { b)Ronaldo e Felipe tiveram desempenhos iguais } \\
\text { porque os dois erraram um chute }\end{array}$ & $\begin{array}{l}\text { a) Tatiana se saiu melhor. } \\
\text { b)Não teve desempenhos iguais. }\end{array}$ \\
\hline
\end{tabular}

Quadro 6: Respostas que contavam erros e acertos Fonte: Elaboração das autoras

Aqueles sujeitos que não responderam ou não justificaram suas respostas para o Problema 1 também erraram o Problema 2. O Quadro 7 resume os resultados encontrados. 


\begin{tabular}{|c|c|c|c|c|c|c|c|c|}
\hline \multirow[t]{3}{*}{ Suj. } & \multicolumn{4}{|c|}{ Problema 1} & \multicolumn{4}{|c|}{ Problema 2} \\
\hline & \multicolumn{2}{|c|}{$\begin{array}{c}\text { a)Quem teve melhor } \\
\text { desempenho? }\end{array}$} & \multicolumn{2}{|c|}{$\begin{array}{l}\text { b)Houve desempenhos } \\
\text { iguais? }\end{array}$} & \multicolumn{2}{|c|}{$\begin{array}{c}\text { a)Quem teve melhor } \\
\text { desempenho? }\end{array}$} & \multicolumn{2}{|c|}{$\begin{array}{c}\text { b)Houve desempenhos } \\
\text { iguais? }\end{array}$} \\
\hline & Resposta & Justificativa & Resposta & Justificativa & Resposta & Justificativa & Resposta & Justificativa \\
\hline S10 & Correta & $\begin{array}{l}\text { Referencial } \\
\text { metade }\end{array}$ & Correta & $\begin{array}{l}\text { Referencial } \\
\text { metade }\end{array}$ & Correta & $\begin{array}{c}\text { Utiliza } \\
\text { razão }\end{array}$ & Correta & $\begin{array}{l}\text { Utiliza } \\
\text { razão }\end{array}$ \\
\hline S4 & Correta & $\begin{array}{l}\text { Conta as } \\
\text { chances }\end{array}$ & Erra & $\begin{array}{l}\text { Conta os } \\
\text { erros }\end{array}$ & Correta & $\begin{array}{l}\text { Utiliza } \\
\text { razão }\end{array}$ & Correta & $\begin{array}{l}\text { Utiliza } \\
\text { razão }\end{array}$ \\
\hline S6 & Correta & $\begin{array}{l}\text { Simula } \\
\text { chances } \\
\text { iguais. }\end{array}$ & Correta & $\begin{array}{c}\text { Simula } \\
\text { chances } \\
\text { iguais }\end{array}$ & Correta & $\begin{array}{l}\text { Utiliza } \\
\text { razão }\end{array}$ & Correta & $\begin{array}{l}\text { Utiliza } \\
\text { razão }\end{array}$ \\
\hline $\mathrm{S} 3$ & Correta & $\begin{array}{l}\text { Conta os } \\
\text { erros }\end{array}$ & Erra & $\begin{array}{l}\text { Conta os } \\
\text { erros }\end{array}$ & Correta & $\begin{array}{l}\text { Utiliza } \\
\text { razão }\end{array}$ & Correta & $\begin{array}{l}\text { Utiliza } \\
\text { razão }\end{array}$ \\
\hline $\mathrm{S} 1$ & Correta & $\begin{array}{l}\text { Referencial } \\
\text { metade }\end{array}$ & Correta & $\begin{array}{l}\text { Referencial } \\
\text { metade }\end{array}$ & Correta & $\begin{array}{l}\text { Conta as } \\
\text { chances }\end{array}$ & Correta & $\begin{array}{c}\text { Não } \\
\text { justifica }\end{array}$ \\
\hline $\mathrm{S} 2$ & Correta & $\begin{array}{l}\text { Referencial } \\
\text { metade }\end{array}$ & Correta & $\begin{array}{l}\text { Referencial } \\
\text { metade }\end{array}$ & Correta & $\begin{array}{c}\text { Não } \\
\text { justifica }\end{array}$ & $\begin{array}{l}\text { Não } \\
\text { responde }\end{array}$ & $\begin{array}{c}\text { Não } \\
\text { justifica }\end{array}$ \\
\hline S5 & Correta & $\begin{array}{l}\text { Conta as } \\
\text { chances }\end{array}$ & Erra & $\begin{array}{l}\text { Conta as } \\
\text { chances }\end{array}$ & Correta & $\begin{array}{l}\text { Utiliza } \\
\text { razão }\end{array}$ & Correta & $\begin{array}{l}\text { Utiliza } \\
\text { razão }\end{array}$ \\
\hline S11 & Erra & $\begin{array}{c}\text { Não } \\
\text { justifica }\end{array}$ & Erra & $\begin{array}{c}\text { Não } \\
\text { justifica }\end{array}$ & Correta & $\begin{array}{l}\text { Conta as } \\
\text { chances }\end{array}$ & Correta & $\begin{array}{c}\text { Não } \\
\text { justifica }\end{array}$ \\
\hline S7 & Erra & $\begin{array}{c}\text { Não } \\
\text { justifica }\end{array}$ & Erra & $\begin{array}{l}\text { Conta os } \\
\text { acertos }\end{array}$ & Correta & $\begin{array}{c}\text { Não } \\
\text { justifica }\end{array}$ & Correta & $\begin{array}{c}\text { Não } \\
\text { justifica }\end{array}$ \\
\hline S8 & Erra & $\begin{array}{l}\text { Não } \\
\text { justifica }\end{array}$ & Erra & $\begin{array}{l}\text { Conta os } \\
\text { erros }\end{array}$ & Correta & $\begin{array}{l}\text { Conta os } \\
\text { erros }\end{array}$ & Correta & $\begin{array}{c}\text { Não } \\
\text { justifica }\end{array}$ \\
\hline S12 & Erra & $\begin{array}{c}\text { Não } \\
\text { justifica }\end{array}$ & Erra & $\begin{array}{c}\text { Não } \\
\text { justifica }\end{array}$ & Correta & $\begin{array}{c}\text { Não } \\
\text { justifica }\end{array}$ & $\begin{array}{l}\text { Não } \\
\text { responde }\end{array}$ & $\begin{array}{l}\text { Não } \\
\text { responde }\end{array}$ \\
\hline S13 & Erra & $\begin{array}{c}\text { Não } \\
\text { justifica }\end{array}$ & Erra & $\begin{array}{c}\text { Não } \\
\text { justifica }\end{array}$ & Correta & $\begin{array}{l}\text { Não } \\
\text { justifica }\end{array}$ & Erra & $\begin{array}{c}\text { Não } \\
\text { justifica }\end{array}$ \\
\hline S14 & Erra & $\begin{array}{l}\text { Conta os } \\
\text { erros }\end{array}$ & Erra & $\begin{array}{l}\text { Conta os } \\
\text { erros }\end{array}$ & Correta & $\begin{array}{c}\text { Não } \\
\text { justifica }\end{array}$ & Erra & $\begin{array}{l}\text { Não } \\
\text { justifica }\end{array}$ \\
\hline S9 & Erra & $\begin{array}{c}\text { Conta os } \\
\text { erros }\end{array}$ & Erra & $\begin{array}{c}\text { Conta os } \\
\text { erros }\end{array}$ & Erra & $\begin{array}{c}\text { Não } \\
\text { justifica }\end{array}$ & Erra & $\begin{array}{c}\text { Não } \\
\text { justifica }\end{array}$ \\
\hline S15 & Erra & $\begin{array}{c}\text { Não } \\
\text { justifica }\end{array}$ & Erra & $\begin{array}{c}\text { Não } \\
\text { justifica }\end{array}$ & Erra & $\begin{array}{c}\text { Não } \\
\text { justifica }\end{array}$ & Erra & $\begin{array}{c}\text { Não } \\
\text { justifica }\end{array}$ \\
\hline
\end{tabular}

Quadro 7: Resumo das respostas dos sujeitos

Fonte: Elaboração das autoras

\section{Discussão}

Nas soluções do Problema 2 não foi identificada a utilização do referencial metade para comparar os desempenhos dos jogadores. Assim, considerou-se que a estrutura deste problema era mais complexa que a do Problema 1. Utilizando a referência proposta por Spinillo (1993) para explicar os elementos constantes em problemas de comparação, mostrada na Figura 1, foi montada uma estrutura de relações parte-parte para os problemas avaliados nesta investigação (Figura 9). 


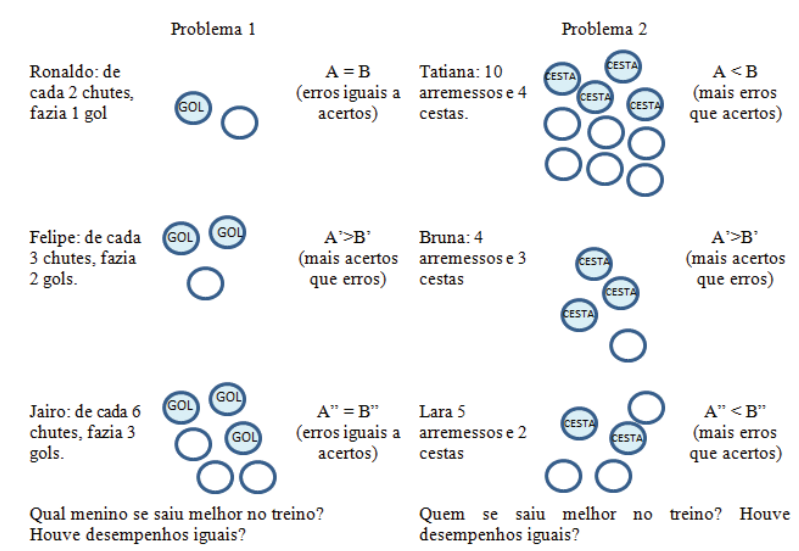

Figura 9: Elementos comparativos de relações parte-parte para os problemas Fonte: Elaboração das autoras

Note-se que apenas o Problema 1 apresentou A=B e A"=B" (erros iguais a acertos para algum jogador), o que favoreceu a utilização acertada do referencial metade. Já o fato de $\mathrm{B}=\mathrm{B}$ '(dois jogadores terem o mesmo número de acertos ou de erros) levou os alunos ao equívoco (também encontrado na pesquisa de Jeong et al., 2011) de comparar os erros e responder equivocadamente que Ronaldo e Felipe teriam desempenhos iguais porque ambos tinham perdido um gol; tal equívoco não poderia ser cometido no Problema 2. Em nenhum dos problemas havia a igualdade $\mathrm{A}+\mathrm{B}=\mathrm{A}^{\prime}+\mathrm{B}^{\prime}=\mathrm{A}$ " $+\mathrm{B}$ " (mesmo número de tentativas para os jogadores), o que facilitaria o estabelecimento das relações de segunda ordem, conforme teorizado por Spinillo (1992, 1993).

A estratégia de montar uma tabela para cada jogador, dobrando ou triplicando o número de tentativas e de acertos de modo a igualar o número de arremessos no Problema 2 não foi utilizada por nenhum aluno, apesar de esta ter sido utilizada na primeira atividade da intervenção, ou seja, no Problema das urnas (em que se igualava o número de bolas brancas e não o total de bolas em cada ação). Assim, os esquemas contidos nas tabelas ilustradas na lousa pela professora e reproduzidas nas fichas (de Ana, Benê e Cadu) não foram transferidos para o Problema 2, o que poderia ter facilitado as justificativas solicitadas. Evidentemente, aqueles alunos que determinaram a razão entre o $\mathrm{n}^{\circ}$ de cestas e o $\mathrm{n}^{\mathrm{o}}$ de $\operatorname{arremessos}\left(\frac{A}{A+B}\right)$ para cada jogadora e reduziram as razões a mesmo denominador, utilizando as representações matemáticas adequadas, devem ter se valido dos esquemas de covariação e invariância.

O estabelecimento das relações de covariação e invariância - que já tinha sido identificado na maioria das respostas dos alunos aos problemas de valor omisso ${ }^{3}$, constantes na

\footnotetext{
${ }^{3}$ Isso pode ser verificado na solução de problemas do tipo: "o barzinho da escola está fazendo uma promoção: a cada 5 pães de queijo comprados, eles dão 2 bombons de brinde; se eu comprar 15 pães de queijo, quantos bombons eu vou ganhar?", em que a maioria dos alunos multiplicou por 3 o número de bombons.
} 
Avaliação 1, conforme apontado por Viana e Miranda (2016) - foi pouco observado nas soluções do Problema 1. Assim, a intervenção didática foi planejada de modo a levar os alunos a estabelecer as mesmas relações como um esquema de assimilação, conforme denominação de Vergnaud (1990). Para o autor, esquema de assimilação é a organização invariante do comportamento e, sendo mais estável, tal esquema passa a ser utilizado pelo sujeito para certa classe de situações. Ao que parece, vários alunos não reconheceram o Problema 2 como pertencente à mesma classe do Problema das urnas, não se valendo do tal esquema para resolvêlo.

Note-se que o preenchimento das fichas que compuseram a intervenção didática requeria a linguagem natural, o que, conforme Vergnaud (1990), permite a transformação dos conceitos-ferramenta em conceitos-objeto. Assim, a ação repetida de colocar uma bola preta a cada duas brancas era simbolizada por $1: 2$, por $2: 4$, por 3:6 etc. e denominada de razão; as tabelas preenchidas e as flechas indicando a covariação e a invariância e também as frases indicando as grandezas proporcionais buscavam a transformação das categorias do pensamento em objetos do pensamento.

$\mathrm{Na}$ resolução do Problema 1, quando S6 justificou que "Felipe [teve melhor desempenho], pois se por exemplo cada um tivesse seis chances, Ronaldo e Jairo fariam 3 e Felipe 4" pareceu estabelecer as relações de covariância e invariância, expressando o conceitoferramenta apenas com palavras. Já S4 utilizou representação simbólica mais potente (VERGNAUD, 1990) para o conceito-objeto de razão no Problema 2; tal problema deve ter sido identificado como pertencente à mesma classe do Problema das urnas, em que foi possível identificar a maior razão e as razões equivalentes (Figura 10).

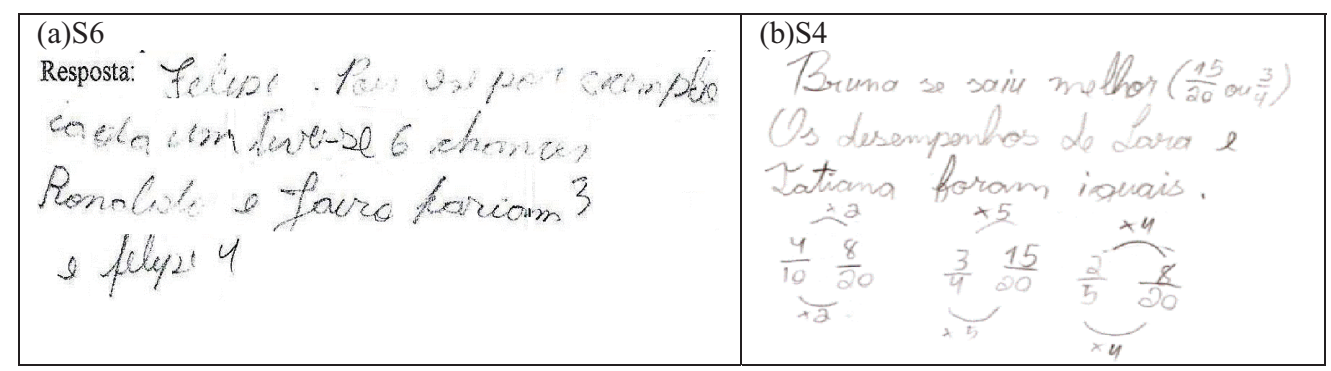

Figura 10: Justificativas para os problemas: (a) com palavras e (b) com representação simbólica Fonte: Elaboração das autoras

O mesmo aluno não se valeu de palavras para expressar o pensamento, o que, de acordo com Vergnaud (1990), pode indicar procedimentos matemáticos já automatizados, apesar de a intervenção didática aplicada não ter como objetivo a fixação de procedimentos de cálculo para 
os problemas apresentados ${ }^{4}$. Aliás, conforme o autor, a "automatização é uma das manifestações mais visíveis do caráter invariante da organização da ação", uma vez que "nossos comportamentos abrangem uma parte de automatismo e outra de decisão consciente" (p.3).

\section{Considerações Finais}

$\mathrm{Na}$ introdução deste trabalho, questionou-se se haveria mudanças de estratégias para os problemas de comparação nas situações antes e após a intervenção. Uma ressalva importante foi que a estrutura do segundo problema era mais complexa que a do primeiro, o que, inevitavelmente, levaria o aluno a empregar novas estratégias, esperando-se que fossem embasadas nos conceitos de razão e proporção introduzidos pela intervenção.

Levou-se em consideração o fato que, conforme Vergnaud (1990), um conceito não pode ser reduzido a sua definição, já que é através de situações e problemas que um conceito adquire sentido para o aluno. Assim, buscou-se apresentar uma classe de situações para as quais os alunos não dispusessem de todas as competências necessárias para resolvê-las, desafiando-os a explorar os dados, fazer tentativas e comparar soluções, valendo-se de esboços de esquemas que podiam ser combinados, o que levaria a novas descobertas. Considerou-se, também, que os esquemas poderiam revelar os conhecimentos em ação do sujeito, ou seja, os elementos cognitivos que permitem as ações operatórias.

As análises das estratégias utilizadas pelos alunos nesta investigação mostraram que boa parte dos alunos já dispunha, antes da intervenção didática, de esquemas de covariação e de variância; entretanto, isto não facilitou a solução correta do problema de comparação - que foi resolvido por outros esquemas disponíveis. Após a intervenção que introduziu os conceitos de razão e proporção, vários alunos conseguiram empregar aqueles esquemas, que surgiram recompostos e enriquecidos. Apesar disso, nem todos os alunos acertaram e justificaram o Problema 2, não conseguindo identificar as razões equivalentes.

Assim, neste trabalho evidencia-se um dos grandes desafios para o professor de matemática: elaborar suas aulas com o objetivo de formar conceitos e desenvolver o raciocínio do aluno e não priorizar a mecanização de procedimentos. No caso do raciocínio proporcional, mesmo considerando a limitação do presente estudo, esta investigação permite mostrar que o processo de aquisição dos conceitos de razão e proporção é de natureza bastante complexa,

\footnotetext{
${ }^{4}$ Note-se que o procedimento de igualar as razões a mesmo denominador não foi trabalhado na intervenção didática, apesar de no Problema das urnas os alunos terem encontrado as razões equivalentes. Estas foram encontradas a partir da elaboração da tabela e não a partir de técnicas mecanizadas.
} 
conforme apontou a literatura, e são necessárias muitas situações para que esses conceitos e os procedimentos requeridos para a solução de problemas adquiram, de fato, sentido para o aluno.

\section{Referências}

BRASIL. Ministério da Educação. Brasil no PISA 2015: análises e reflexões sobre o desempenho dos estudantes brasileiros / OCDE-Organização para a Cooperação e Desenvolvimento Econômico. - São Paulo: Fundação Santillana, 2016a. Disponível em:<

http://download.inep.gov.br/acoes_internacionais/pisa/resultados/2015/pisa2015_completo_final_baix a.pdf $>$ Acesso em 08 nov 2017.

BRASIL. Conselho Nacional de Secretaria de Educação. Base Nacional Comum Curricular. Brasília: Distrito Federal, 2016b. Disponível em: $<$ http://basenacionalcomum.mec.gov.br/a-base $>$ Acesso em 10 nov 2017.

BOYER, T. W.; LEVINE, S. L. HUTTENLOCHER, J. Development of Proportional Reasoning: Where Young Children Go Wrong. Developmental Psychology, V. 44, No. 5, 1478-1490, 2008. Disponível em: $<$ https://www.ncbi.nlm.nih.gov/pmc/articles/PMC2597581/> Acesso em 08 nov 2017.

CARNEIRO, V. C. G. Contribuições para a Formação de Professores de Matemática Pesquisador nos Mestrados Profissionalizantes na Área de Ensino. Bolema, ano 21, n. 29. Rio Claro (SP), 2008.

Disponível em:<

http://www.mat.ufrgs.br/ vclotilde/publicacoes/mar172008revisadoVeraClotilde.pdf $>$ Acesso em 08 nov 2017.

COSTA, S.; PONTE, J. P. O Raciocínio Proporcional dos alunos do $2^{\circ}$ ciclo do Ensino Básico. Revista da Educação, Vol. XVI, no 2, p.65-100, 2008.

JEONG, Y.; LEVINE, S. C.; HUTTENLOCHER, J. The Development of Proportional Reasoning: Effect of Continuous Versus Discrete Quantities. Journal of Cognition and Development, 8:2, 237 256, 2007. Disponível em:<

https://cogdevlab.uchicago.edu/sites/cogdevlab.uchicago.edu/files/uploads/JeongLevineHutt 2007.pdf > Acesso em 08 nov 2017.

LESH, R.; POST, T.; BEHR, M. Proportional Reasoning. In J. Hiebert \& M. Behr (Eds.) Number Concepts and Operations in the Middle Grades. Reston, VA: Lawrence Erlbaum \& National Council of Teachers of Mathematics, 1988, p. 93-118. Disponível em:< http://www.cehd.umn.edu/ci/rationalnumberproject/88 8.html> Acesso em 08 nov 2017.

MAGINA, S.; SANTOS, A.; MERLINI, V. L. O raciocínio de estudantes do Ensino Fundamental na resolução de situações das estruturas multiplicativas. Ciênc. Educ., v. 20, n. 2, p. 517-533. Bauru, 2014. Disponível em: $<$ http://www.scielo.br/scielo.php?pid=S1516-

$73132014000200517 \&$ script $=$ sci abstract\&tlng=pt $>$ Acesso em 08 nov 2017.

MARANHÃO, C; MACHADO, S. Uma meta-análise de pesquisas sobre o pensamento proporcional. Educar em Revista, $n^{o}$. Especial 1, p. 141-156, UFPR. Curitiba, 2011. Disponível em:< http://revistas.ufpr.br/educar/article/viewFile/22614/14844> Acesso em 08 nov 2017.

MIRANDA, J. A. Desenvolvimento do raciocínio proporcional: uma sequência didática para o sexto ano do ensino fundamental. Dissertação (mestrado profissional) - Programa de Pós-Graduação em Ensino de Ciências e Matemática, Universidade Federal de Uberlândia, 2016. Disponível em:< http://www.ppgecm.ufu.br/sites/ppgecm.ufu.br/files/Anexos/Bookpage/Disserta\%C3\%A7\%C3\%A3o \%20Juliene\%20-\%20Biblioteca.pdf> Acesso em 10 nov 2017. 
MOREIRA, M.A.; NARDI, R. O mestrado profissional na área de Ensino de Ciências e Matemática: alguns esclarecimentos. R.B.E.C.T. vol 2, n.3, p. 1-9, 2009. Disponível em: <

https://periodicos.utfpr.edu.br/rbect/article/view/549/398> Acesso em 04 set 2017.

MORTON, C, H. An investigation into ixth grade students' understanding of ratio and proportion.

International Journal for Research in Mathematics Education, V. 4, N.1, p.68-80, 2014.

Disponível em: $<$ http://www.sbembrasil.org.br/ripem/index.php/ripem/article/view/88 $>$ Acesso em 08 nov 2017.

ONUCHIC, L. de La R.; ALLEVATO, N. S. G. Proporcionalidade através da Resolução de Problemas no Curso Superior de Licenciatura em Matemática. Seminário Internacional de Pesquisa em Educação Matemática, 6, Pirenópolis, Goiás, 2015 Anais... Sociedade Brasileira de Educação Matemática, 2015. Disponível em:< http://www.sbembrasil.org.br/visipem/anais/story.html> Acesso em 08 nov 2017.

PONTE, J. P. da; SILVESTRE, A. I.; GARCIA, C.; COSTA, S. O desenvolvimento do conceito de proporcionalidade direta pela exploração de regularidades. Tarefas para $1^{\circ}$ e $2^{\circ} \mathrm{Ciclos}$ do Ensino Básico: Materiais de Apoio ao Professor. 2010. Disponível em:

$<$ http://www.apm.pt/files/_Materiais_Proporcionalidade_(IMLNA) 4cfc0dcb29b46.pdf $>$ Acesso em 08 nov 2017.

SPINILLO, A. G. A importância do referencial de "metade" e o desenvolvimento do conceito de proporção. Psicologia: Reflexão e Crítica, Vol. 8, N 3, p.305-331, 1992. Disponível em:< http://periodicos.unb.br/index.php/revistaptp/article/view/20476> Acesso em 08 nov 2017.

. As relações de primeira-ordem em tarefas de proporção: uma outra explicação quanto às dificuldades das crianças. Psicologia: Reflexão e Crítica, Vol. 9, № 2, p. 349-364, 1993. Disponível em: < http://periodicos.unb.br/index.php/revistaptp/article/view/20493> Acesso em 08 nov 2017.

.O Papel de Intervenções Específicas na Compreensão da Criança sobre Proporção. Psicologia: Reflexão e Crítica, Vol. 15, No 3, p. 475-487, 2002. Disponível em:<

http://www.scielo.br/scielo.php?script=sci abstract\&pid=S0102-

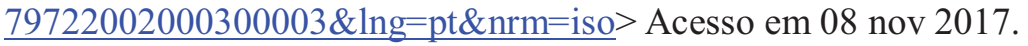

TORRE, J.; TJOE, H.; RHOADS, K.; LAM, D. Conceptual and Theoretical Issues in Proportional Resoning. International Journal for Studies in Mathematics Education. V.6 (1), p. 21-38, 2013.Disponível em: $<$ http://pgsskroton.com.br/seer/index.php/jieem/article/view/99 $>$ Acesso em 08 nov 2017.

VERGNAUD, G. La théorie des champs conceptuels. Recherches en Didactique des

Mathématiques. Tradução: Juan D. Godino. V. 10, n. 23, p. 133-170. Grenoble, 1990. Disponível em:

$<$ http://www.ecosad.org/laboratorio-virtual/images/biblioteca-virtual/bibliografiagc/teoria-de-camposconceptuales-vergnaud-1990.pdf> Acesso em 08 nov 2017.

. A criança, a matemática e a realidade: problemas do ensino da matemática na escola elementar. Tradução: Maria Lucia Faria Moro; revisão técnica: Maria Tereza Carneiro Soares. Curitiba: Ed. da UFPR, 2009.

VIANA, O. A. Elaboração de problemas e os sentidos dados para o conceito de razão: um estudo introdutório com alunos da licenciatura. Seminário PIBID/UFU: Integração de Projetos, 4, Uberlândia, 2013. Anais... UFU, Uberlândia, 2013.

VIANA, O. A.; MIRANDA, J. A. O raciocínio proporcional e as estratégias de resolução de problemas de valor omisso e de comparação. Revemat, Florianópolis (SC), v.11, n. 1, p. 202-213, 2016. Disponível em: $<$ https://periodicos.ufsc.br/index.php/revemat/article/view/43255 $>$ Acesso em 08 nov 2017. 